\title{
Editorial
}

\section{Surgery for the mind}

It is hardly surprising that discussion of psychosurgery tends to provoke powerful emotions. On the one hand there seems to be an intuitive human revulsion at the very idea of destroying parts of a person's brain in order to change forever some aspect of his experience or behaviour. This revulsion may be paradoxically reinforced by both a primitive Cartesian dualist belief that it cannot be done anyway and, more importantly, by horror stories of the human zombies produced by some of the early operations. Proponents of psychosurgery on the other hand, infuriated by ill informed criticism, argue enthusiastically for the beneficial, sometimes 'almost miraculous' effects of modern operations upon people previously crippled mentally and socially by mental disorder for which all else has proved therapeutically useless. The arguments are rehearsed in this issue of the fournal by Mr Larry Gostin, legal director of MIND and, in a commentary on Gostin's article, by Dr Paul Bridges, psychiatrist to the Geoffrey Knight Psychosurgical Unit in London.

So far as the facts are concerned there seems little doubt, even in the absence of prospective controlled trials, that what Bridges calls 'contemporary' psychosurgery - that is lesions placed by carefully controlled stereotactic techniques in the subcaudate white matter of the frontal lobes with or without additional lesions in each cingulum and in the genu of the corpus callosum - can produce impressive improvement. Thus in severe and previously intractable depression, anxiety, and obsessional neurosis some 40-60 per cent of patients have been assessed as recovered (grade I, free of symptoms) or much improved (grade $\mathrm{II}_{2}$ mild residual symptoms reremaining). ${ }^{1,2,3}$ Furthermore with the modern operations only a very small incidence of side effects and in particular personality changes (other than amelioration of symptoms of the disease) has been reported. Thus the study of 209 patients by Goktepe et $a l^{2}$ indicated that some 7 per cent manifested personality changes, all of which were assessed as relatively minor ones such as talkativeness, outspokenness, increased smoking and eating. No case of emotional blunting was reported. In the follow-up study of 66 patients by Mitchell Heggs et $\mathrm{al}^{3}$ there was a similarly small incidence of personality changes, again of relatively minor degree. Clearly, when less radical treatments have failed modern psychosurgery can benefit carefully selected patients.
Nonetheless major problems remain. The first is one $\stackrel{\varpi}{\%}$ of maximising the gains of this hard won technique and $\vec{O}$

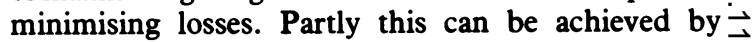
organisational changes. At present a majority of $\vec{\sigma}$ psychosurgical operations, in Britain at least, are carried out in psychosurgical centres in which it is possible to develop and maintain the appropriate surgical and associated skills and to pursue relevant research. $A_{\rightarrow}^{\omega}$ large minority of such operations however are still $\vec{G}$ being carried out in ordinary neurosurgical units on ano occasional basis often using relatively hazardous? freehand techniques. This state of affairs, as both Gos- $c s$ tin and Bridges agree, is undesirable. There is debate $\mathbb{D}$ whether it should be changed by law or by voluntary $\mathbb{\triangle}$ arrangements within the profession. The latter seemo obviously preferable: but if they are not obtained soon $\stackrel{\mathbb{D}}{2}$ social pressures may well result in the former. One way $\vec{\oplus}$ or another change is surely appropriate.

A second major problem is that of consent. appears that the policy of the main psychosurgisilo units in Britain is either that they will never, or efse only extremely rarely, operate on patients without their consent, and one unit at least will not operate on any patient compulsorily detained under the Menta $\stackrel{\Omega}{\Rightarrow}$ Health Act. As Gostin says 'the imposition of any formo of treatment without consent is a serious intrusion on the dignity of an individual'. In the case of psycho-? surgery not only is it particularly serious an intrusion but, he also suggests, it may be illegal.

A serious complication here is whether compulsorily: detained patients, people with certain sorts of mental 3 disturbance and also children, are capable of givingo valid consent. Whatever the legal or philosophical answers to these questions are, the medical profession has no special competence to prejudge them alone. In? cases where informed consent is not obtained or is obtained in circumstances which make its validity doubtful it is surely desirable either that psychosurgerys should not be performed at all, or else that it be per formed only under the most exceptional and string 슨 ently controlled circumstances. It is in this context thaf a multidisciplinary review committee may be appro? priate, as proposed in the Government White Pape? reassessing the Mental Health Act $1959 .^{4}$

It is not clear from Gostin's paper whether his pro posals for a review committee follow those of the Whit: Paper and thus apply only to patients from whom valieक consent to psychosurgery cannot clearly be obtained $\frac{f}{\rho}$ or whether he (and MIND) seek to extend such multio disciplinary reviews to any potential candidate fo 
psychosurgery. If the latter, then Bridges' criticisms are well-founded: the contract between an informed and validly consenting adult and his surgeon needs no additional supervision by multidisciplinary committees.

Quite different are the cases of compulsorily detained patients, children and others whose consent, even if obtainable, might not be valid. Here are complex issues requiring thorough multidisciplinary analysis. Moreover even if doctors alone were competent to make such an analysis it is a basic requirement of justice that it should not only be done but also clearly be seen to be done. Where valid consent is lacking treatment becomes coercion and a matter for general concern. In such circumstances the innovation of multidisciplinary groups such as those proposed by Gostin and in the Government White Paper deserves serious consideration.

\section{References}

${ }^{1}$ Strom-Olsen, R and Carlisle, S (I97I). Bifrontal stereotactic tractotomy. British journal of psychiatry, II8, I4I-I 54.

${ }^{2}$ Goktepe, E O, Young, L B and Bridges, P K (1975). A further review of the results of stereotatic subcabdate tractotomy. British journal of psychiatry, 126, 270-280.

${ }^{3}$ Mitchell-Heggs, N, Kelly, D and Richardson, A (1976). Stereotactic limbic leucotomy - a follow-up at 16 months. British joumal of psychiatry, 128, 226-240.

${ }^{4}$ Department of Health and Social Security (1978). Review of the Mental Health Act 1959, Cmnd 7320, London, HMSO.

\section{Good television - indifferent ethics}

On three consecutive nights earlier this year Granada Television interrogated doctors and others on what they would do in various hypothetical morally complex situations. Lawyers, manifesting varying degrees of aggression, took turns at hoisting their quarries upon their own petards. Conflicting opinions were elicited, absolute claims were made and then undermined, muddy waters thoroughly stirred. We learned that some doctors would never betray a patient's confidence, no matter what the cost to society might be; that others would do so in exceptional circumstances; and that administrators might bypass the lot by showing hospital records tom the police at their own discretion (the administratos who dropped this bombshell added that he woul\$ not even discuss the matter with the doctor con cerned 'so as not to put him in an impossible? situation').

Different opinions were obtained on consent to vas ectomy in various complicated circumstances; orf over-riding a patient's known aversion to ECT; and or sterilisation of a sexually active mentally subnormaks youth with a family history of Huntingdon's Chorea! In the last programme a wide range of attitudes to euthanasia was exposed. Not surprisingly there was some reluctance to part with what was sometimes explosive information and the trans-Atlantic court $\overline{\bar{B}}$ room drama scenes were often tense as the medicaf hares were run to ground by Granada's legal beagles (i山 warning perhaps to British medicine of the relationship between the two professions current in Nortk? America?).

Some congratulations to Granada for opening up this important area for public discussion and for revealin 8 so clearly the wide diversity of medical opinion abouf many medico-moral issues. But good television as al this was, it totally failed to allow time or latitude for proper discussion of why the doctors and others held. their conflicting views and how, if at all, these views fitted within coherent networks of moral beliefs. M@iaP philosophy - which is what such discussion amountsit - is bound to be complex and cannot possibly accommodated within the long question-short answe technique so beloved of lawyers, television producero and often, let it be said, doctors too. But all attemp at complexity were rigorously suppressed on the Granada programmes and whenever a participant trie 9 to develop the discussion the interrogator leapt sprightly to another question.

Nonetheless the programmes will have proved invaluable if all the health professionals who saw them and especially medical teachers, have asked themselves what they personally are doing to facilitate the meticup. ous, dispassionate and often complex discussions if moral philosophy which such 'hypotheticals' deman from all who may be involved in the corresponding realities.

.

